University of South Carolina

Scholar Commons

$4-1991$

\title{
The Effects of Practice Progressions on Learning Two Volleyball Skills
}

\author{
Karen E. French \\ University of South Carolina - Columbia, kfrench@mailbox.sc.edu \\ Judith E. Rink \\ University of South Carolina - Columbia, jrink@mailbox.sc.edu \\ Linda Rikard \\ Amy Mays \\ Columbia College - Columbia, South Carolina \\ Susan Lynn \\ Florida State University
}

See next page for additional authors

Follow this and additional works at: https://scholarcommons.sc.edu/pedu_facpub

Part of the Education Commons

\author{
Publication Info \\ Published in Journal of Teaching in Physical Education, Volume 10, Issue 3, 1991, pages 261-274. \\ http://journals.humankinetics.com/jtpe-contents \\ (C) 1991 by Human Kinetics Publishers, Inc.
}

This Article is brought to you by the Physical Education, Department of at Scholar Commons. It has been accepted for inclusion in Faculty Publications by an authorized administrator of Scholar Commons. For more information, please contact digres@mailbox.sc.edu. 


\section{Author(s)}

Karen E. French, Judith E. Rink, Linda Rikard, Amy Mays, Susan Lynn, and Peter H. Werner 


\title{
The Effects of Practice Progressions on Learning Two Volleyball Skills
}

\author{
Karen E. French, Judith $\mathbb{E}$. Rink, Linda Rikard, \\ Amys Mays, Susan Lymn, and Peter Werner
}

The purpose was to compare the effectiveness of practice progressions on learning the volleyball serve and overhead set. Ninth-grade students were randomly assigned to three groups. Each group practiced the volleyball serve and set for 60 trials over 6 days. The progression group practiced four levels of difficulty of the set and serve. The criterion group began practice at the beginning level of difficulty and had to achieve an $80 \%$ success rate before practicing at a more advanced level. The third group practiced the AAHPERD volleyball skill tests for the serve and set for all 60 trials. At the end of practice, all subjects were posttested using these AAHPERD tests. The results indicated the progression and criterion groups had higher posttest scores than the third group. Profiles of the success rates across acquisition for each group showed that students in the third group and low-skilled students in the progression and criterion groups did not improve during practice. Students with some initial skill in the progression and criterion groups exhibited high success rates for acquisition and improvement. These results indicate that sequencing practice in progressive levels of difficulty enhances retention when task difficulty is appropriate for the learner. However, no condition was effective when task difficulty was inappropriate for the learner.

Many practitioners have advocated instructional experiences designed to present learners with progressions of content that vary from simple to complex. The basic assumption was that beginning levels of skill needed to be mastered before more complex versions were presented. These assumptions have surfaced in instructional texts in education (Tyler, 1949) and physical education (Rink, 1985; Vogel \& Seefeldt, 1988) and have been proposed by psychologists (Fischer, 1980; Gagné, 1968). All of these authors emphasized the hierarchical nature of skill

K.E. French, J.E. Rink, and P. Werner are with the Dept. of P.E., U. of South Carolina, Columbia, SC 29208. L. Rikard is with the Dept. of P.E., East Carolina U., Greenville, NC 27834. A. Mays is with the Dept. of P.E., Columbia Coll., Columbia, SC 29203. S. Lynn is with the Dept. of P.E., Florida State U., Tallahassee, FL 32306. 
development and the importance of learning subskills prior to introducing more complex skills. Despite these frameworks, there has been little empirical research to directly support the use of practice progression in motor skill instruction.

Rink (1985) identified the extension task as one of four movement tasks employed in the process the teacher uses to develop motor content in an instructional setting. The extension task changes the conditions of the previous task to either reduce or increase the task's complexity for the learner. The teacher can manipulate practice conditions in many ways: by using a progression of parts; by modifying equipment; by changing the spacial relationships for practice, the intent of the skill, the number of people involved, and the number of repetitions of the same skill; and by sequencing practice of one skill with another skill. This idea (that teachers who manipulate the content complexity for the learner enhance student achievement) has a great deal of intuitive appeal from an educational practice perspective. However, there is little research supporting such a notion or providing theoretical justification for practice progressions (Werner \& Rink, 1989).

Most of the literature that supports the need for extension in student practice comes from indirect sources in education and motor learning. The most direct evidence is reported in the few studies that have examined "mastery learning." Mastery learning can be characterized by careful structure, small incremental steps, frequent monitoring of progress, and a feedback-corrective process (English, 1983). For example, the teacher would present the content in small, increasing levels of difficulty. A performance criterion (mastery) for each level of task difficulty would be established. Each student would be required to achieve the performance criterion for a given level of task difficulty before being allowed to practice the next, progressively difficult level. The basic premise is that prerequisite skills should be mastered before the introduction of more complex skills. Authors have compared mastery learning techniques with traditional instruction in classroom environments (Burnes, 1979; Hyman \& Cohen, 1979). The results of these studies showed increased retention under mastery learning instruction. Two studies have demonstrated that mastery learning is beneficial in learning motor skills as well (Ashy \& Lee, 1984; Blakemore \& Roland, 1986). Blakemore and Roland (1986) compared mastery and traditional methods of instruction in learning volleyball skills in seventh- and eighth-grade students. A similar comparison was made using throwing accuracy with kindergarten and first-grade subjects by Ashy and Lee (1984). Both studies indicated an advantage in learning by the mastery group.

Research in three areas of motor learning also provides guidelines for developing progressions that aid in transfer to more complex skills. The first area is research examining whole-versus-part practice. This topic has been studied extensively. Naylor and Briggs (1963) suggested that the decision to practice a skill as a whole or in parts depends on the organization and complexity of the task. Complex tasks were defined as tasks having a number of components and requiring much attention throughout the movement. Tasks with many interrelated parts were considered high in organization. Naylor and Briggs suggested that tasks high in complexity and low in organization would be practiced best in parts (e.g., dance, 
some gymnastics sequences). Tasks low in complexity and high in organization would be practiced best as a whole (e.g., jumping, weightlifting). Analyzing tasks according to the continuum of complexity and organization could aid teachers in planning extensions to facilitate student learning.

There are other considerations involved in developing content progressions. Schema theory (Schmidt, 1975) suggests that practicing variations of the skill during acquisition leads to better retention and transfer of the skill. The theory proposes that the learner abstracts four sources of information during practice to form schema, or rules that aid in the reproduction of the task, or similar responses using the same generalized motor program. These sources include initial conditions, sensory consequences, information concerning movement outcome, and movement parameters. One prediction of the theory is the variability-of-practice hypothesis, which suggests that practicing variations of a task by varying the four sources of information produces greater transfer to novel tasks that use the same generalized motor program. Therefore, providing extensions to vary the initial conditions in which the movement is performed should enhance student learning and transfer to tasks using the same generalized motor program.

A third area of research in motor learning provides suggestions for the arrangement of practice trials. Several studies have shown a phenomena known as contextual interference (Lee \& Magill, 1983; Shea \& Morgan, 1979). These studies showed that practicing a skill under low contextual-interference conditions (repetitive practice of the same skill) leads to poorer retention of the skill than high contextual-interference conditions (intermittent spacing of practice, such as random practice schedules). The advantage of spacing practice trials to avoid repetition of one task has been documented in numerous studies (Del Rey, 1989; Lee \& Magill, 1983), including one study that used the complex task of badminton (Goode \& Magill, 1986). These studies suggested that repeatedly practicing the same task with no change or variability produces lower rates of learning.

We have used the literature from education, motor learning, and psychology as a multidisciplinary framework to begin addressing effective ways of developing content to enhance student learning. The literature provided several guidelines for content development. Decisions concerning whole-versus-part practice should be determined by the degree of organization and the complexity of the task. The initial conditions in which the task is practiced should be varied, and repetition of the same task should be avoided. Simpler practice conditions should be introduced early in practice to aid in development of prerequisite skills necessary for more difficult versions of the task.

This paper reports our initial work to establish a relation between certain types of extension and student achievement. If the proposed guidelines are important to student learning, practicing progressive task difficulty should enhance student learning in comparison with practicing the most difficult level of the task. Practicing progressive difficulty would avoid task repetition, provide variability 
of task conditions, and provide a simple to complex task sequence. In this study, two groups practiced with progressive levels of difficulty. One group (progression) practiced a set number of trials at four stages of complexity. The second group (criterion group) had to achieve an $80 \%$ success rate at the two beginning levels of complexity before they could advance to the fourth level. A third group (final test) practiced the actual test conditions for the skills. If practice arranged in progressive levels of difficulty enhances learning, the first two groups should score higher on retention. Most teachers are limited in the time available for students to master a given content. We chose to control the number of practice trials because this simulated actual teaching situations more appropriately. All subjects practiced the same number of trials.

\section{Method}

Subjects

The subjects were 53 students from a private school, recruited from two intact coeducational physical education classes and from a study hall.

\section{Pretest Procedures}

All subjects were pretested on the overhead set and the serve using the procedures outlined in the Volleyball Skills Test Manual (AAHPERD, 1967). The set test requires the subject to redirect the ball from a $45^{\circ}$-angle toss and set the ball over a 10-foot-high rope onto a target area on the floor. The serve test requires the subject to serve over the net from the baseline into areas of the court associated with point values. A higher point value is achieved for serves that clear the net and land near the baseline and the sidelines.

The subjects from the physical education classes $(N=36)$ were then randomly assigned to one of three practice groups. The other subjects served as a control group $(N=17)$. An analysis of variance was conducted to determine if there were group differences on the pretest. No differences were observed, $p>.05$. The groups were subdivided by skill level: A pretest score of less than 3 for the set and less than 8 for the serve was considered low skill. Higher scores were considered average skill. All groups had approximately equal numbers of subjects identified in each skill group.

\section{Practice Procedures}

The three practice groups consisted of a group that practiced the actual serve and overhead-set tests every class period (final-test group), a group that practiced a fixed number of trials in a specific practice progression (progression group), and a group that was required to obtain an $80 \%$ success rate at the first and second level of difficulty in the practice progression (criterion group). The control group did not practice the volleyball skills during the study.

The levels of difficulty in practice progressions were determined a priori by the experimenters, had been pilot tested for their appropriateness with the serve and overhead set, and had been utilized in an earlier study (French, Rink, $\&$ Werner, 1990). Table 1 provides a brief outline of the progression of difficulty in the serve and the overhead set. 
Table 1

\section{Progressions of Task Difficulty}

Level

Scoring

Serve

1. Stand 10 feet from the wall. Hit the ball

0 -ball does not hit wall above 8 feet over an 8 foot high line using overhand serve.

2. Serve from midcourt over the net to the baseline.

1 -ball hits the wall above 8 feet line

0 -ball does not go over the net

1-ball goes over the net but lands farther than 10 feet from the baseline

2-ball lands in the court within 10 feet of the baseline

3. Serve the ball over the net from the baseline to the opposite baseline.

0 -ball does not go over the net

1-ball goes over the net but lands farther than 10 feet from the baseline

2-ball lands in the court within 10 feet of the baseline.

4. Test condition.

As outlined by AAHPERD (1967).

Set

1. Self toss, move under the ball, and catch in a good setting position.

0 -ball is not caught

1 -ball is caught but knees are not bent, back is not straight, ball is not above the forehead

2-ball is caught in good setting position

2. Set the ball over a 10 foot rope from a partner toss.

0 -ball does not go over the rope

1-ball goes over the rope.

0 -ball does not go over the rope

1-ball goes over rope

2-ball goes over rope in the intended direction, right or left

4. Test condition

As outlined by AAHPERD (1967)

All experimental groups received instruction in the serve and set prior to beginning practice. A verbal description and visual demonstration of each skill was presented. Each subject was required to demonstrate the appropriate movement pattern for each skill without the use of a ball. The purpose of this instruction was to assure that each subject had an initial understanding of the skills before practice under different conditions was introduced.

Practice was conducted in a gymnasium using four modified volleyball courts. Each level of difficulty was assigned a practice station. Students met in their experimental groups with one instructor at the beginning of class and were directed to the appropriate area for the level of difficulty for a given day. Sufficient number of regulation volleyballs were available for practice.

The three groups practiced the overhead set and the serve for 10 trials each day for 6 days. Each student was instructed to score each practice trial of the serve and the set. Students either recorded practice trials individually or worked 
with partners. One instructor was available at each practice station to assist and monitor scoring and student practice and remained at that station for all 6 practices. The instructor provided a verbal presentation of specific cues for the task and a visual demonstration before students began practice. Each task presentation, both verbal and visual, was determined prior to the study. Thus, each group received the same verbal and visual instructions for a given level of difficulty in the overhead set and the serve. Instructors also provided individual feedback. However, feedback was inconsistent due to the management needs of the group.

All subjects including the control group were posttested on the AAHPERD serve and set tests 3 days after the end of practice.

\section{Results}

The scores for the serve and the overhead-set tests were analyzed in separate $4 \times 2 \times 2$ (Practice group $\times$ Skill level $\times$ Pre/post) univariate repeated measures ANOVAs. The significance level was set at .05. The results for the serve indicated significant effects for group, $F(3,44)=3.60, p<.02$; pre/post, $F(1,44)=17.50, p<.01$; skill, $F(1,44)=100.91, p<.01$; and group by pre/post interaction, $F(3,44)=4.73, p<.01$. Significant effects for the set were found for group, $F(3,44)=4.14, \quad p<.02 ;$ skill, $F(1,44)=41.85, p<.01$; pre/post, $F(1,44)=17.91, p<.01$; and a trend for group by pre/post interaction, $F(3,44)=2.65, p<.06$. The low-skilled subjects had lower scores on the serve and the set than the average-skilled subjects. Group and pre/post main effects were superceded by the Group $\times$ Pre/post interaction for both skills. Subjects in the control and final-test groups did not improve from pretest to posttest. Subjects in the progression and criterion groups improved from pretest to posttest. The mean pretest and posttest scores for each skill level in each practice group are presented in Figure 1.

\section{Profiles}

One question of interest concerned the individual subject's response to the task in each practice group. To assess the student's response, we calculated the student's success rate at practicing a given task. Each day, the scores for each subject's practice were converted to percent by dividing the number of points for each practice trial by the total number of points possible for a given day of practice at a given level. The scores for the pretest and posttest were converted to percentage by a similar process. The pretest, practice, and posttest success rates for each individual were graphed to determine if there were patterns within each skill level and practice group during acquisition. Trends were identified in each practice group for each skill level. The patterns provide useful information to describe individual student's responses to the tasks during practice. A summary of individual patterns of success rates are presented in the next section.

Serve. Profiles for low-skilled subjects in the final-test, progression, and criterion groups for the serve are presented at the top of Figure 2. Low-skilled subjects in the final-test group started with little success, practiced with little success, and exhibited little success on the posttest. One student showed minimal progress. However, no one exceeded $15 \%$. The serve from the backcourt was not an appropriate level of difficulty for these students. 

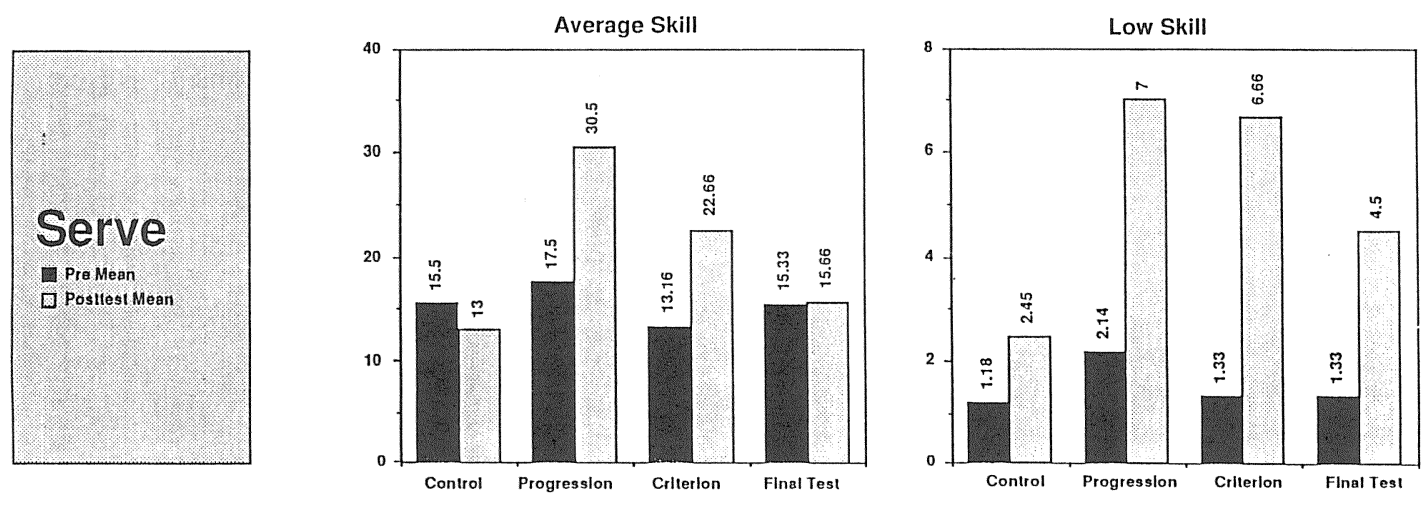

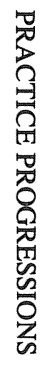
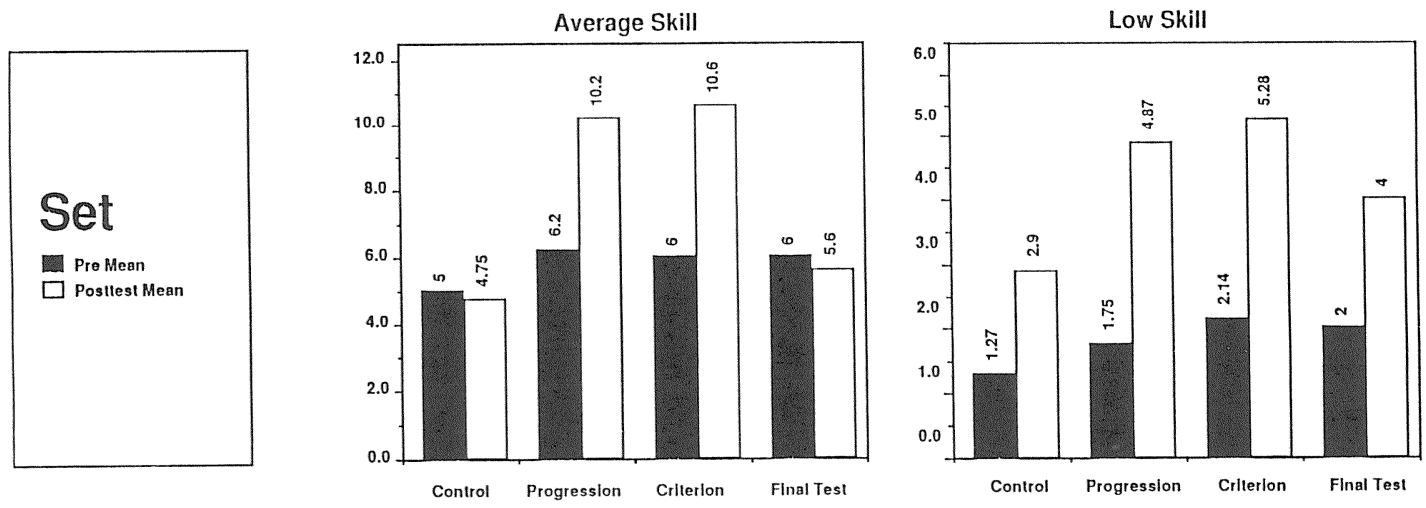

Figure 1 - Pretest and posttest means for low and average skill in each group. 
Serve

Final Test

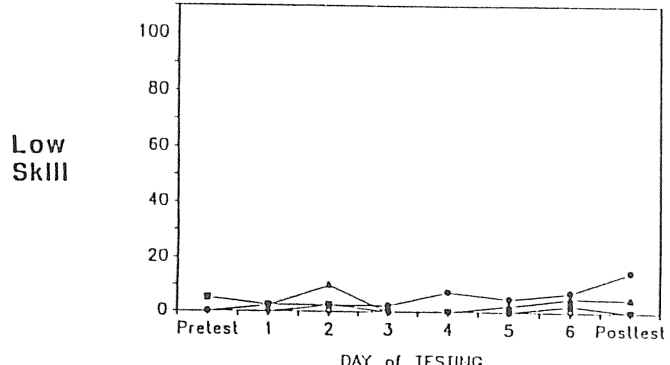

DAY of TESIIHG

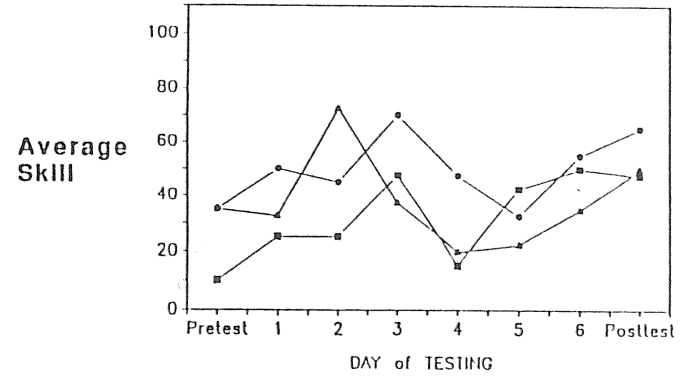

Progression
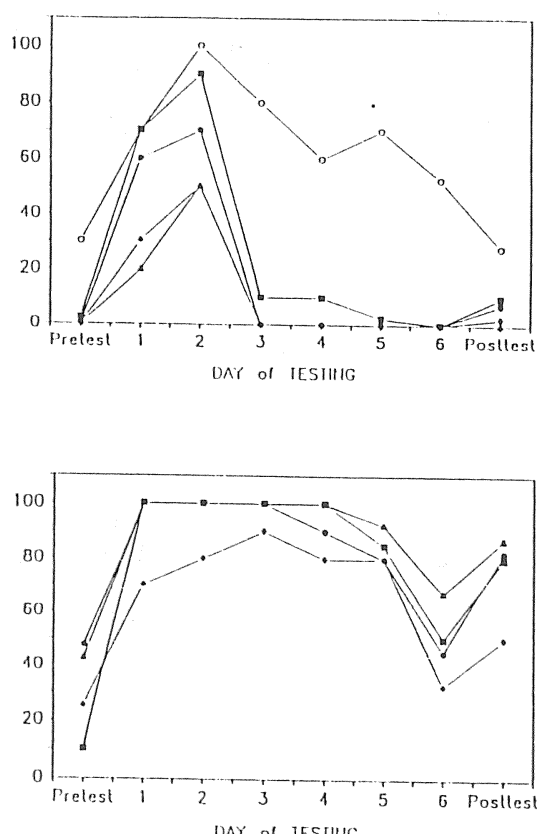

Figure 2 - Profiles of success rates across acquisition in the serve. 
Low-skilled students in the progression group began with no ability to get the ball across the net. They experienced moderate levels of success at the first two levels on the first 2 days. When asked to serve the ball from full court, force production was an obvious problem. Slight progress was shown on the posttest for two of these students.

Success rates fluctuated for low-skilled students in the criterion group. None of these students ever achieved high enough success rates at the beginning levels to proceed to the fourth. Three students spent 4 days at the first level. The steady increases in success rates through these 4 days do not reflect an unmotivated learner. These students were not able to strike a ball even when low levels of force production were required. Little progress was made on the posttest. Regardless of the practice condition, low-skilled students made little progress in the serve. The lack of improvement seemed to be related to problems producing force.

Profiles for the average-skilled students in the final-test, progression, and criterion groups for the serve are presented at the bottom of in Figure 2. The profile for average-skilled students in the final-test group shows a cyclical pattern. Initial increases on the first 3 days declined on the 4th day then increased on the 5th and 6th days. We attribute the decline to a loss of motivation. These students possessed some initial skill and did show some gain in performance. The remaining subjects in the final-test group (not shown in Figure 2) exhibited profiles that fluctuated between $20 \%$ and $40 \%$. Most of the profiles were relatively flat, indicating few learning trends. These students did not show gain on the posttest scores. Two students regressed.

Students in the progression group began with some skill in the serve and maintained a high degree of success at the first three levels during the first 5 days. Success rates dropped on the 6th day at the fourth level but improved on the posttest. Students profited from the progression and experienced higher levels of success throughout the progression and on the posttest than subjects who practiced the final test.

Students in the criterion group moved through the first two levels during the first 2 days of practice. Success rates dropped on the 3rd day when practice at the fourth level was introduced. By the 4th day, most success rates increased and a high degree of success was maintained during the remaining practice and on the posttest. These students showed considerable improvement from pretest to posttest.

In summary, the students with initial skill in both the criterion and the progression groups had higher success rates during the lower levels of practice than the final-test group. More importantly, the criterion and progression groups were able to achieve and maintain higher success rates once they reached the fourth level of difficulty.

Overhead Set. Profiles for the low-skilled subjects in the final-test, progression, and criterion groups for the set are presented at the top of Figure 3. The profiles for the final-test group for both skill levels are similar. Most students exhibited considerable variability from day to day and showed little or no improvement on the posttest.

Two patterns emerged for low-skilled students in the progression group. Both patterns show deterioration in success rates as the level of difficulty increases. The students shown in solid lines maintained success rates above 50\% 
Final Test

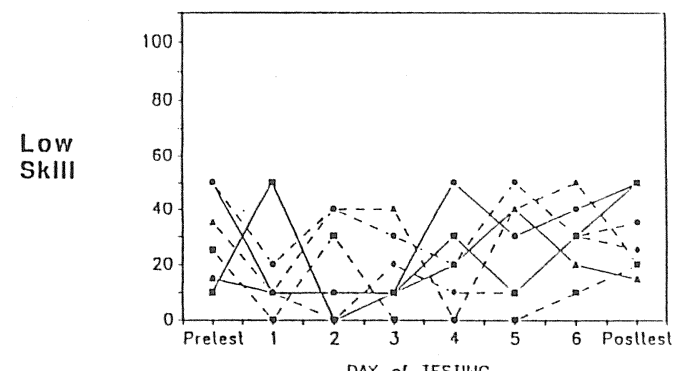

DAY of IESIIING

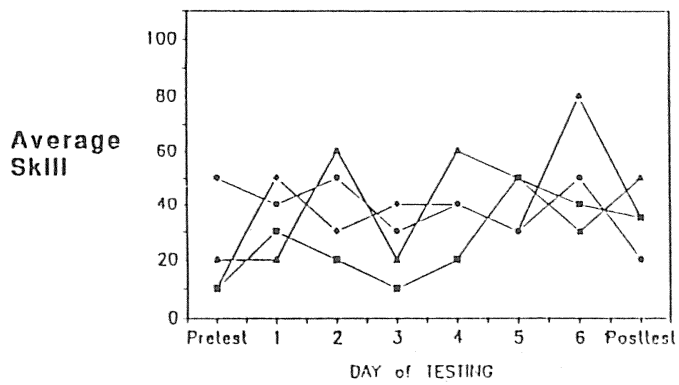

Set

Progression

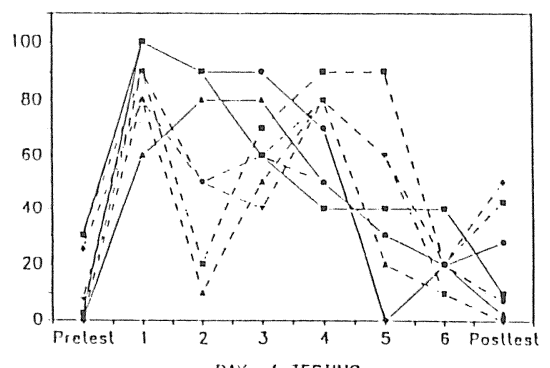

DAY of TESIING

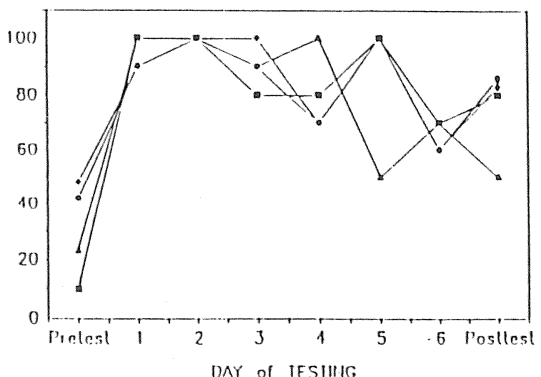

Criterion

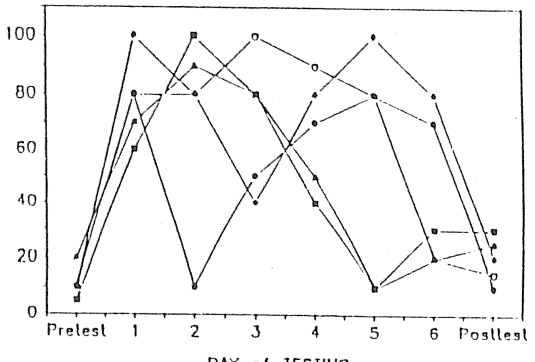

DAY of IESTIHG

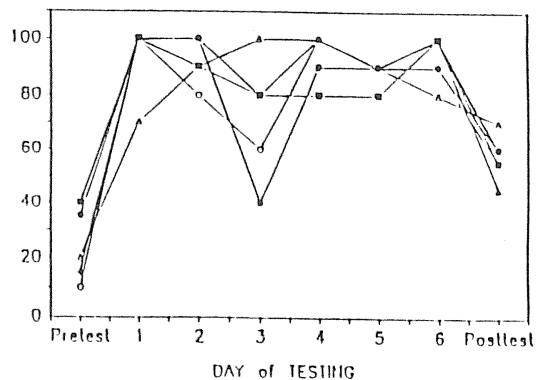

Figure 3 - Profiles of success rates across acquisition in the overhead set. 
at the first two levels. Their performance declined when they reached the third and fourth levels. The students shown in broken lines initially had difficulty with the second level, or getting height to clear the rope. Their success rates then improved until they reached the fourth level. The success rate drops dramatically at this last level. Two students showed improvement on the posttest; the other students did not improve.

Only one of the low-skilled students in the criterion group reached the fourth level during practice. A drop in success rate was noted each time a student advanced to a higher level and when a student practiced a given level more than 3 days consecutively. Little progress was made from pretest to posttest.

The profiles for the average-skilled student in each group are presented at the bottom of Figure 3. The profiles for average-skilled students in the final-test group were similar to the pattern for the low-skilled student. The profiles for average-skilled subjects in the progression group showed a high level of success during the first 5 days of practice. Success rates dropped when students began practice at the fourth level. All of the students improved from pretest to posttest. The profiles for the average-skilled students in the criterion group mirror those of the progression group. High levels of success were achieved at the first two levels. Success rates declined for the first practice at the fourth level, improved the next day of practice, and were maintained the last 3 days of practice. All students improved on the posttest.

\section{Discussion}

The results of this study do not support practice of the final test as the most efficient practice to produce learning of complex skills such as the volleyball serve and overhead set. Both groups that practiced simpler variations of the task exhibited greater change from pretest to posttest. These findings suggest that some types of extension may be more beneficial to student learning. Skill level interacted with the effects of the practice conditions. Students with some initial skill profited more from progressions of difficulty than repeated practice of the final test. The low-skilled student made little or no progress as measured by the posttest regardless of the practice arrangement.

There are alternative explanations for the superiority of practice conditions with progressions of difficulty. One of the strongest explanations is that the volleyball set and serve are complex motor skills. Students in this study needed the complexity of the task reduced during the early stages of practice. Profiles for the average-skilled students in the progression and criterion groups clearly indicate that higher success rates were achieved during acquisition when these groups reached the test conditions than the final-test group at any time during practice. Low-skilled students in the progression and criterion groups showed some progress when task difficulty was appropriate. However, as soon as the task became more difficult, performance drastically deteriorated. The final-test condition was obviously inappropriate for low-skilled students. If task difficulty was inappropriate for a student, no condition was effective.

Several authors have emphasized the importance of developing prerequisite skills needed for mastery of more complex skills (Gagné, 1968; Hunter, 1971; 
Popham \& Baker, 1970; Rink, 1985; Rosenshine, 1983). This idea is not new and is presented in greater detail in the previously cited works. The results of this study support the view of developing prerequisite skills before introducing complexity.

Reduction of task complexity is not the only explanation. If task complexity were the only explanation, we should have seen a larger difference between lowand average-skilled subjects in the final-test group. Neither groups improved during acquisition or on posttest scores. Several skilled students in the finaltest group made initial progress during acquisition, lost interest, and actually regressed. Practice with progressive difficulty in the criterion and progression groups facilitated learning for the average-skilled student as evidenced by acquisition profiles and posttest scores.

Practice in the criterion and progression groups involved change of the task focus; whereas the final-test group repetitively practiced the same task with the same goal. Change in the task focus may have facilitated effortful practice in one of two ways. First, motivation may have been a factor. Students in the final-test group may have become bored by practicing the same task repeatedly. Several students in this group improved the first 3 days and then regressed. A second possibility is that changing the task focus may have enhanced the integration of additional information into the solution of the movement problem. Change in task focus may have facilitated more effortful processing of the movement by forcing the student to resolve the movement problem in a different movement context. This explanation is similar to explanations of contextual interference (Lee \& Magill, 1983; Magill, 1989). Changing the goal or the intent of the movement (i.e., varying initial conditions) to focus on one aspect of the movement may have enhanced the development of the recall schema (Schmidt, 1975) by highlighting important features of the correct movement pattern. Thus, variations of the practice goal at each level of difficulty may have led to more effortful practice and better retention.

The reduction in task complexity, increased motivation, and more effortful processing of the movement task probably all interact to produce greater retention. The question for future research becomes, How can we best (a) provide practice opportunities that afford the learner experience at appropriate levels of task difficulty and (b) vary the conditions to produce effortful practice?

Several observations of the low-skilled student deserve mentioning. No practice condition was effective for them. Clearly, the level of task difficulty was too great for these students. Motivation was not a problem for the students in the progression and criterion groups. Even though their progress was slow or nonexistent in some cases, their success profiles showed a consistent but slow pattern of improvement. Low-skilled students scored little after the serve progression asked them to get the ball over the net from half court. Several lowskilled students in the criterion group spent many days at the first level of difficulty before they were allowed to move to the next level. A few students in this group never made it out of this first level.

We have several questions relative to low-skill students. First, would some of these students eventually develop skill in these tasks? These students obviously need more practice time at low levels of difficulty. A second question involves problems inherent with these low-skilled students: Most of their problems were 
related to the inability to produce force. This was evident in both the serve and the set. Both of these questions have implications for curriculum and instruction. Motor skill acquisition takes time. Several studies are beginning to show that much practice time is needed to produce change in the performance of complex gross motor skills (Masser, 1987; Rink, Werner, Hohn, Ward, \& Timmermans, 1986; Silverman, 1985; Werner \& Rink, 1989). Given the time necessary to develop complex motor skills, we must begin to address these issues in order to design instructional experiences and curricula that enhance fundamental abilities in students before more complex skills are introduced.

\section{References}

AAHPERD. (1967). Volleyball skills test manual. Reston, VA: AAHPERD.

Ashy, M., \& Lee, A.M. (1984, March). Effects of a mastery learning strategy on throwing accuracy and technique. Paper presented at the annual conference of the American Alliance for Health, Physical Education, Recreation, and Dance, Anaheim, CA.

Blakemore, C.L., \& Roland, P. (1986, April). A comparison of achievement of students taught psychomotor skill using mastery learning, non-mastery, and no drills methods. Paper presented at the annual conference of the American Alliance for Health, Physical Education, Recreation, and Dance, Cincinnati, $\mathrm{OH}$.

Burnes, W.B. (1979). Mastery Learning: Does it work? Educational Leadership, 37, $110-113$.

Del Rey, P. (1989). Training and contextual interference effects on memory and transfer. Research Quarterly for Exercise and Sport, 60, 342-347.

English, F. (Ed.). (1983). Fundamental curriculum decisions. Alexandria, VA: Association for Supervision and Curriculum Development.

Fischer, K.W. (1980). A theory of cognitive development: The control and construction of hierarchies of skill. Psychological Review, 87, 477-531.

French, K.E., Rink, J.E., \& Werner, P.H. (1990). Effects of contextual interference on retention of three volleyball skills. Perceptual and Motor Skills, 71, 179-186.

Gagné, R.M. (1968). Contributions of learning to human development. Psychological Review, 75, 117-191.

Goode, S., \& Magill, R.A. (1986). The contextual interference effects in learning of three badminton serves. Research Quarterly for Exercise and Sport, 57, 308-314.

Hunter, M. (1971). The teaching process. In D. Allen \& E. Seifman (Eds.), The teacher's handbook (pp. 146-157). Greenview, IL: Scott, Foresman.

Hyman, J.S., \& Cohen, S.A. (1979). Learning for Mastery: Ten Conclusions after fifteen years and three thousand schools. Educational Leadership, 37, 104-109.

Lee, T.D., \& Magill, R.A. (1983). The locus of contextual interference in motor skill acquisition. Journal of Experimental Psychology: Learning, Memory, and Cognition, 9, 730-746.

Magill, R.A. (1989). Motor learning concepts and applications (3rd. ed.). Dubuque, IA: W.C. Brown Publishers.

Masser, L. (1987). The effect of refinement on student achievement in a fundamental motor skill in grades $\mathrm{K}$ through 6. Journal of Teaching in Physical Education, $\mathbf{6}$, 174-181. 
Naylor, J., \& Briggs, G. (1963). Effects of task complexity and task organization on the relative efficiency of part and whole training methods. Joumal of Experimental Psychology, 65, 217-244.

Popham, W., \& Baker, E. (1970). Systematic instruction. Englewood Cliffs, NJ: Prentice-Hall.

Rink, J.E. (1986). Teaching physical education for learning. St. Louis, MO: Times Mirror Mosby.

Rink, J.E., Werner, $\mathbb{F} . \mathbb{H}$., Hohn, R., Ward, D., \& Timmermans, $\mathbb{H}$. (1986). The differential effects of three teachers over a unit of instruction. Research Quarterly for Exercise and Sport, 57, 132-138.

Rosenshine, B.V. (1983). Teaching functions in instructional programs. The Elementary School Journal, 83, 335-352.

Schmidt, R.A. (1975). A schema theory of discrete motor skill learning. Psychological Review, 76, 383-393.

Shea, J.B., \& Morgan, R.L. (1979). Contextual interference effects on the acquisition, retention, and transfer of a motor skill. Joumal of Experimental Psychology: Human Learning and Memory, 5, 179-187.

Silverman, S. (1985). Relationship of engagement and practice trials to student achievement. Journal of Teaching in Physical Education, 5, 13-21.

Tyler, $\mathbb{R}$. (1949). Basic principles of curriculum and instruction. Chicago: The University of Chicago Press.

Vogel, P., \& Seefeldt, V. (1988). Program design in physical education. Indianapolis: Benchmark Press.

Werner, P.H. \& Rink, J.E. (1989). Case studies of teacher effectiveness in second grade physical education. Journal of Teaching in Physical Education, 8, 280-297. 